\title{
Effects of Plasminogen, Streptokinase, and Their Equimolar Complexes with Pyruvate Kinase on the Human Neuroblastoma IMR-32 Cells
}

\author{
A. A. Romanovskaya* and V. N. Nikandrov \\ Institute of Physiology, National Academy of Sciences of Belarus, Minsk \\ *e-mail:a-a-r@tut.by \\ Received August 23, 2006
}

\begin{abstract}
The system of extracellular proteolysis consisted of plasminogen (PGn), its active protease, plasmin, and PGn activators and their inhibitors affect the growth, differentiation, and proliferation of nervous cells both under normal and pathological conditions. The purpose of our investigation was to study the effects of exogenous PGn, its activator, streptokinase (SK), pyruvate kinase (PK), and their equimolar complexes on morphological and functional properties of IMR-32 neuroblastoma cells. It has been found that PGn, SK, PK, and their complexes stimulate cell proliferation during 1-3 days of incubation. We also observed increased DNA, RNA, and protein content. The low-lactate dehydrogenase (LDH) efflux indicated that the addition of the proteins we assayed to the culture medium prevented the development of degenerative processes caused by serum deprivation. The levels of extracellular PGn-activator activity, as measured by the fibrinolytic method, increased in the presence of SK. The SK effect vanished if SK was in the complex with PK on the 3rd day of cultivation. New original facts were obtained to testify the probability of initiation of neoplastic transformation and tumor growth potentiation.
\end{abstract}

Key words: neuroblastoma, plasminogen, pyruvate kinase, proliferation, streptokinase.

Abbreviations: LDH, lactate dehydrogenase; PGn, plasminogen; PK, pyruvate kinase; SK, streptokinase; IGF, insulin-like growth factor; PAI, plasminogen activator inhibitor; tPA, tissue plasminogen activator; uPA, urokinase plasminogen activator; uPAR, receptor of urokinase PGn activator

DOI: $10.1134 /$ S1990519X07050069

The studies of recent decades have proved the essential role of several proteases in growth and development of the central nerve system. Of great importance is the system of extracellular proteolysis that, in addition to zymogene itself and its active form, plasmin, includes activators of plasminogen (PGn), of urokinase (uPA) and tissue (tPA) types and inhibitors of these activators (PAI).

Neuroblastoma ranks second place in the occurrence of solid tumors in children. Neuroblastoma cells secrete uPA, tPA, and PAI (Benjamin et al., 1989b). $\mathrm{uPA}$ is bound to specific receptor (UPAR) and activates PGn, converting it into PA. PA is implicated in proteolysis and tissue degradation. Highly tumorogenic cells have enhanced levels of PGn associated with cells (Liu et al., 1984). PGn itself significantly increases the migration of neuroblasts (Puglianiello et al., 2000). $0.5 \times 10^{-7} \mathrm{M}$ PGn stimulates the proliferation of neuroblastoma cells (Menouny et al., 1997).

Streptokinase (SK) is produced by $\beta$-hemolytic streptococcus A; C; and G, a representative of human and animal microflora. It is a strong PGn activator in non-proteinase pathways. However, the protein properties and effects have not been well examined.

Since in living systems proteins can not function individually, there is a high possibility of intermolecular protein complex formation that will entail changes in their initial biological activity. It was found that PGn and SK are able to form stable equimolar complexes with enzymes of carbohydrate metabolism, in particular, pyruvate kinase (PK) (Nikandrov et al., 1997). Experiments in vitro demonstrated that SK modulates the metabolism and electrophysiological parameters of nerve cells (Nikandrov et al., 2003c; Romanovskaya, 2005).

The aim of the paper presented is to elucidate the effect of PGn, SK, and equimolar complexes with PGn on structural and functional characteristics of human neuroblastoma IMR-32.

\section{MATERIALS AND METHODS}

Reagents. PGn samples isolated from $\beta$-globulin fractions and purified by affinity chromatography on 
lysine-Sepharose were kindly provided by Dr. N.S. Pyzhova (Institute of Epidemiology and Microbiology, Health Ministry, Belarus). The properties of PGn used in experiments were described previously (Nikandrov et. al., 1997). PK from rabbit muscle (EC 2.7.1.40) was purchased from Reanal company (Hungary), SK was from OAO Belmedpreparat (Belarus), and NADH and sodium pyruvate was from Sigma-Aldrich (USA). Other reagents are products from CIS countries.

Cell culture. IMR-32 was obtained from the Russian Cell Culture Collection (Institute of Cytology, RAS, St. Petersburg). Cells were cultured in DMEM medium (Sigma, USA) supplemented with $10 \%$ fetal calf serum (Hyclone, Belgium) and $10 \mu \mathrm{g} / \mathrm{ml}$ gentamycin at $37^{\circ} \mathrm{C}$ in $5 \% \mathrm{CO}_{2}$ and $90 \%$ humidity. They were subcultured for 4-5 days each at $90 \%$ cell density. For experiments, cells from nearly confluent cultures were detached from the vessel surface with EDTA/trypsin mixture $(1: 3)$ and plated in a 35-mm Petri dish (Sarstedt, USA) with a density of 50000 cells per $\mathrm{cm}^{2}$. Cells were grown in DMEM medium with $10 \%$ fetal calf serum for $24 \mathrm{~h}$. Then the growth medium was replaced by a medium with $0.5 \%$ fetal calf serum. On day 3 , the growth medium was exchanged for the medium without serum with the addition of PGn, PK, SK, or equimolar PGn$\mathrm{PK}$ or SK-PK complexes. Control cultures were grown in serum-free media without additions. Proteins and their complexes were used in concentrations $10^{-7}, 10^{-9}$ and $10^{-11} \mathrm{M}$. The agents were sterilized by filtration through $0.22 \mu \mathrm{m}$ filters. Equimolar complexes were prepared immediately before an experiment as described earlier (Nikandrov et al., 1997). The results were registered 1 and 3 days after the additions.

Cell viability was estimated with Trypan blue staining $(0.4 \%$ solution in phosphate buffer, $\mathrm{pH} 7.2)$. The number of stained (dead) and unstained (viable) cells were counted in Goryaev's chamber. The viable cell fraction was calculated according to the formula $A=$ $(B-C) / B \times 100 \%$, where $A$ is viable cells (\%), $B$ is total cell number, and $C$ is the number of dead cells. Proliferation index (PI) was calculated as the ratio of final cell number to the initial (seeded) cell number.

Cell culture medium was put into tubes and centrifuged at $150 \mathrm{~g}$ for $5 \mathrm{~min}$ to sediment nonadhesive cells. Supernatant was combined with cells detached from plates by routine technique. Lactate dehydrogenase (LDH) activity was measured in the culture medium.

Determination of DNA, RNA and protein content. Nucleic acid content was determined by the sequential elimination of the acid-soluble fraction and lipids with alkaline and acid hydrolysis (Schmidt and Thannhauser, 1945). Cell pellet was treated with $1 \mathrm{ml}$ $0.3 \mathrm{M} \mathrm{HClO}_{4}$ and placed on ice for 15 min to provide the complete sedimentation of the acid insoluble fraction. Then the samples were centrifuged at 2000$3000 \mathrm{~g}$ for $10-15 \mathrm{~min}$. The pellet was washed twice with $0.1 \mathrm{M} \mathrm{HClO}_{4}$ and suspended in $0.5 \mathrm{ml}$ water, after which $0.5 \mathrm{ml}$ of $0.6 \mathrm{M} \mathrm{KOH}$ was added. The tubes were incubated at $37^{\circ} \mathrm{C}$ for $1 \mathrm{~h}$ and then placed on ice to stop hydrolysis. Tubes with $2 \mathrm{ml} 0.6 \mathrm{M} \mathrm{HClO}_{4}$ added were kept in ice for $15 \mathrm{~min}$ before being centrifuged at 2000$3000 \mathrm{~g}$ for $10 \mathrm{~min}$. Supernatant was used for RNA determination. $2 \mathrm{ml} 0.5 \mathrm{M} \mathrm{HClO}_{4}$ were added to the pellet. The pellet was resuspended and put in a water bath at $80^{\circ} \mathrm{C}$ for $20 \mathrm{~min}$ for hydrolysis. DNA content was determined in these samples. Acid and protein content were assayed with spectrophotometer CARY-100 (Varian, Australia). The results were calculated by Cary Win UV software (2003) with RNA/DNA application.

LDH activity in cell culture medium was measured by the routine spectrophotometric method (Koh and Choi, 1987). Samples ( $300 \mu 1$ were added to the freshly prepared substrate-buffer mixture $(0.76 \mathrm{mM}$ sodium pyruvate and $85 \mu \mathrm{l} \mathrm{NADH}$ in $0.1 \mathrm{M}$ potassium-phosphate buffer, $\mathrm{pH}$ 7.5) at room temperature. Absorption of the reaction mixture was measured on the spectrophotometry at $340 \mathrm{~nm}$ for $1 \mathrm{~min}$. NADH reduction was registered during pyruvate conversion into lactate by $\mathrm{LDH}$. Enzyme activity was measured as nM NADH at $1 \mathrm{~min}$ per $1 \mathrm{mg}$ protein.

PGn-activating cell capacity was assayed by lysis of fibrin gel with PGn as described previously (Pyzhova et al., 1996). Fibrin plates were prepared in Petri dishes. Gel was produced by mixture of $10 \mathrm{ml} 0.3 \%$ human fibrinogen in physiological solution and $0.2 \mathrm{ml}$ thrombin solution in distilled water. Plates with gel were kept at room temperature for $2 \mathrm{~h}$, after which samples were layered on the gel surface. Cells incubated with $10^{-7} \mathrm{M}$ tested proteins for 1 or 3 days were washed at $150 \mathrm{~g}$ for 5 min. $2 \times 10^{6}$ washed cells were suspended in fresh DMEM medium. $30 \mu \mathrm{l}$ of suspension was put in plates, covered with fibrin, and incubated at $37^{\circ} \mathrm{C}$. Lysis area $\left(\mathrm{mm}^{2}\right)$ was measured after $20 \mathrm{~h}$.

Cells were visualized under the light inverted phase-contrast microscope (OPTON, Germany), 24 or $72 \mathrm{~h}$ after the testing agents were added to the cultures.

Statistical analysis. The results are presented as the mean value and the standard deviation from no less than three independent measurements. Statistical significance was evaluated by a U-test for nonparametric samplings. $p<0.05$ was considered significant. Statistical treatments were done with Statistica 6.0 software.

\section{RESULTS}

Proliferation and nucleic acid content in IMR-32 cells treated with PGn, PK, SK, or their complexes. $10^{-7}-10^{-9} \mathrm{M}$ PGn in $24 \mathrm{~h}$ stimulated metabolism, but did not affect proliferation. Cell number was unaltered, but RNA and protein content increased by $38-55 \%$ and $27-49 \%$, respectively. $10^{-7}-10^{-9}$ M SK augmented DNA by $34-39 \%$, RNA-24-30\%, and protein-43$45 \%$. Proliferation index (PI) increased by $50 \%$ only in cultures treated with $10^{-7}$ M SK. $10^{-11}$ M SK or PGn did not affect cell number and nucleic acid content. In cells treated with $10^{-7}-10^{-11} \mathrm{M}$ PGn, RNA and protein con- 
Table 1. Nucleic acid content and proliferation in human neuroblastoma IMR-32 cells treated with pyruvate kinase (PK), plasminogen (PGn), streptokinase (SK), or their equimolar PGn-PK or SK-PGn complexes after 1-day cultivation

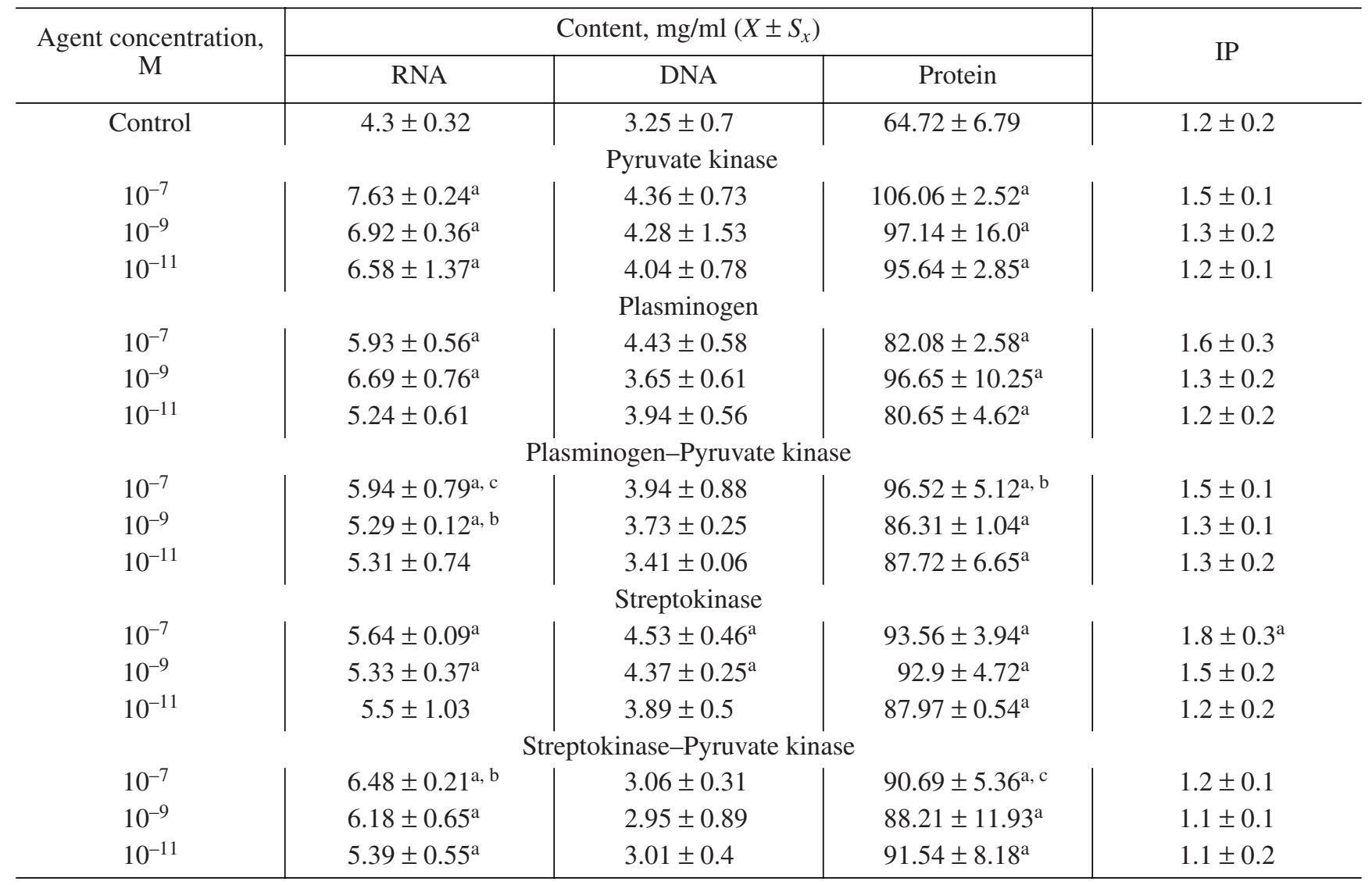

a The difference with control is significant.

$\mathrm{b}$ The difference between equimolar complex and agents they are composed is significant.

${ }^{\mathrm{c}}$ The difference from PGn equimolar concentration is significant. Statistical comparison was made by Mann-Whitney test for nonparametric samples $(p<0.05)$.

tent increased by $53-77 \%$ and $48-64 \%$, respectively. Cell number in cultures with $10^{-7} \mathrm{M}$ PGn was higher $(25 \%)$ than in control cultures; however, IP was not altered. The effect of the equimolar PK-PGn complex was similar to PGn. The SK-PK complex increased RNA content by $25-50 \%$ and protein by $36-40 \%$. DNA content and cell number in cultures treated with this complex was similar to those in control cultures (Table 1).

Suppression of metabolism and inhibition of cell proliferation was observed in neuroblastoma cultures grown in serum-free medium for 3 days. DNA and protein content were unchanged, whereas RNA content was reduced to $50 \%$. These results are presumably explained by the high metabolism rate of the tumor cell and the requirements for nutrients and growth factors of fetal calf serum. PGn in each concentration induced an increase in DNA content by $21-61 \%$, RNA by $71-$ $118 \%$, and protein by $38-88 \%$. In comparison with the control, PGn sustained cell proliferation and PI increased by $45-91 \%$. SK also supported IMR-32 cell viability. SK treatment for 3 days augmented DNA content by $41-185 \%$, RNA by $41-90 \%$, and protein by $53-$
145\%. IP increased by $54-154 \% \cdot 10^{-11}$ SK did not affect the RNA amount, which was comparable with the amount found after 1 day of cultivation. The addition of PK in any concentration to the culture medium resulted in an increase in DNA content by $132-281 \%$, RNA by $171-231 \%$, protein by $154-273 \%$, and IP by $154-273 \% .10^{-7} \mathrm{M}$ PGn-PK complex enlarged the content of DNA by $93 \%$, RNA by $289 \%$, protein by $152 \%$, and IP by $191 \%$. Lower complex concentration, $10^{-9} \mathrm{M}$, slightly influenced the DNA amount, whereas RNA content was enhanced by $213 \%$, protein by $119 \%$ and IP by $127 \% .10^{-11}$ complex raised the RNA amount by $100 \%$; other parameters were unchangeable. In 3 days, the PK-SK complex increased the content of RNA by 95-206\%, DNA by $102 \%$ (only in $10^{-7} \mathrm{M}$ concentration), and protein by 40-150\%. Macromolecule content in cells cultivated with $10^{-9}$ and $10^{-11}$ complexes for 1 and 3 days were comparable. $10^{-7}$ and $10^{-11} \mathrm{M}$ complex increased IP by 45-154\% (Table 2).

Free or complex bound proteins apparently have different effects on nucleic acid and protein content, as 
Table 2. Nucleic acid content and proliferation in human neuroblastoma IMR-32 cells treated with pyruvate kinase (PK), plasminogen (PGn), streptokinase (SK) or their equimolar PGn-PK or SK-PGn complexes after 3-day cultivation

\begin{tabular}{|c|c|c|c|c|}
\hline \multirow{2}{*}{$\begin{array}{c}\text { Agent concentration, } \\
\text { M }\end{array}$} & \multicolumn{3}{|c|}{ Content, $\mathrm{mg} / \mathrm{ml}\left(X \pm S_{x}\right)$} & \multirow{2}{*}{ IP } \\
\hline & RNA & DNA & Protein & \\
\hline Control & $2.87 \pm 0.11$ & $3.37 \pm 0.2$ & $56.39 \pm 3.25$ & $1.1 \pm 0.1$ \\
\hline \multicolumn{5}{|c|}{ Pyruvate kinase } \\
\hline $10^{-7}$ & $9.51 \pm 0.57^{\mathrm{a}}$ & $12.85 \pm 2.28^{\mathrm{a}}$ & $203.7 \pm 17.26^{\mathrm{a}}$ & $4.1 \pm 0.3^{\mathrm{a}}$ \\
\hline $10^{-9}$ & $9.31 \pm 0.43^{\mathrm{a}}$ & $12.3 \pm 1.73^{\mathrm{a}}$ & $198.91 \pm 17.82^{\mathrm{a}}$ & $3.9 \pm 0.1^{\mathrm{a}}$ \\
\hline $10^{-11}$ & $7.77 \pm 1.65^{\mathrm{a}}$ & $7.82 \pm 3.43^{\mathrm{a}}$ & $141.88 \pm 45.63^{\mathrm{a}}$ & $2.8 \pm 0.2^{\mathrm{a}}$ \\
\hline \multicolumn{5}{|c|}{ Plasminogen } \\
\hline $10^{-7}$ & $6.25 \pm 1.06^{\mathrm{a}}$ & $4.74 \pm 0.97^{\mathrm{a}}$ & $92.55 \pm 9.61^{\mathrm{a}}$ & $1.8 \pm 0.1^{\mathrm{a}}$ \\
\hline $10^{-9}$ & $6.55 \pm 1.66^{\mathrm{a}}$ & $5.42 \pm 1.57^{\mathrm{a}}$ & $105.94 \pm 26.95^{\mathrm{a}}$ & $2.1 \pm 0.1^{\mathrm{a}}$ \\
\hline $10^{-11}$ & $4.91 \pm 0.38^{\mathrm{a}}$ & $4.09 \pm 0.86$ & $78.05 \pm 10.36^{\mathrm{a}}$ & $1.6 \pm 0.2^{\mathrm{a}}$ \\
\hline \multicolumn{5}{|c|}{ Plasminogen-Pyruvate kinase } \\
\hline $10^{-7}$ & $11.42 \pm 1.59^{\mathrm{a}, \mathrm{d}}$ & $6.5 \pm 2.85^{\mathrm{a}, \mathrm{c}}$ & $142.3 \pm 33.79^{\mathrm{a}, \mathrm{b}}$ & $3.2 \pm 0.3^{\mathrm{a}, \mathrm{b}}$ \\
\hline $10^{-9}$ & $8.99 \pm 0.87^{\mathrm{a}}$ & $4.2 \pm 0.68$ & $123.59 \pm 11.75^{\mathrm{a}, \mathrm{c}}$ & $2.5 \pm 0.3^{\mathrm{a}, \mathrm{c}}$ \\
\hline $10^{-11}$ & $5.75 \pm 1.36^{\mathrm{a}}$ & $2.48 \pm 1.12$ & $75.39 \pm 13.38$ & $1.5 \pm 0.3$ \\
\hline \multicolumn{5}{|c|}{ Streptokinase } \\
\hline $10^{-7}$ & $5.47 \pm 1.22^{\mathrm{a}}$ & $9.62 \pm 1.07^{\mathrm{a}}$ & $138.42 \pm 15.5^{\mathrm{a}}$ & $2.8 \pm 0.1^{\mathrm{a}}$ \\
\hline $10^{-9}$ & $4.06 \pm 1.02^{\mathrm{a}}$ & $5.75 \pm 0.67^{\mathrm{a}}$ & $90.57 \pm 5.01^{\mathrm{a}}$ & $1.8 \pm 0.2^{\mathrm{a}}$ \\
\hline $10^{-11}$ & $3.07 \pm 0.11$ & $4.74 \pm 0.69^{\mathrm{a}}$ & $86.06 \pm 6.08^{\mathrm{a}}$ & $1.7 \pm 0.2^{\mathrm{a}}$ \\
\hline \multicolumn{5}{|c|}{ Streptokinase-Pyruvate kinase } \\
\hline $10^{-7}$ & $8.78 \pm 0.62^{\mathrm{a}, \mathrm{e}}$ & $6.83 \pm 2.0^{\mathrm{a}, \mathrm{c}}$ & $141.3 \pm 14.3^{\mathrm{a}, \mathrm{c}}$ & $2.8 \pm 0.2^{\mathrm{a}, \mathrm{c}}$ \\
\hline $10^{-9}$ & $6.8 \pm 2.03^{\mathrm{a}, \mathrm{c}}$ & $3.39 \pm 0.33$ & $90.52 \pm 18.22^{\mathrm{a}, \mathrm{c}}$ & $1.8 \pm 0.2^{\mathrm{a}, \mathrm{c}}$ \\
\hline $10^{-11}$ & $5.6 \pm 0.49^{\mathrm{a}, \mathrm{c}}$ & $3.11 \pm 0.12$ & $79.07 \pm 4.56^{\mathrm{a}, \mathrm{c}}$ & $1.6 \pm 0.2^{\mathrm{a}, \mathrm{c}}$ \\
\hline
\end{tabular}

a The difference with control is significant.

$\mathrm{b}$ The difference between equimolar complex and agents they are composed is significant.

c The difference from PGn equimolar concentration is significant. Statistical comparison was made by Mann-Whitney test for nonparametric samples $(p<0.05)$.

well as on cell proliferation. Thus, IMR-32 cells incubated with PGn, PK, or a PGn-PK complex for 1 day had increased RNA and protein content. The amount of these biomolecules in cells grown with $10^{-7} \mathrm{M}$ PK was higher than in cells cultivated with PGn or PK-PGn. DNA concentration in cells incubated with PK or equimolar SK-PK complex was similar to control cells, whereas $10^{-7}-10^{-9} \mathrm{M}$ SK induced an enlarged amount RNA, DNA, and protein, as well as stimulated proliferation.

In 3 days, RNA content in cells cultivated with $10^{-7}$ M PGn-PK complex was comparable with that in cells grown with $10^{-7} \mathrm{M} \mathrm{PK}$ and higher than in cells incubated with the same dose of PGn. The DNA amount in cultures with the complex did not differ from that in cells cultivated with PGn. Protein content was higher than in cells incubated with PGn but lower than in cells treated with PK. IP was lower than in PK treated cultures but higher than in PGn cultures. $10^{-7} \mathrm{M} \mathrm{SK}-\mathrm{PK}$ complex induced cell RNA higher than with SK alone. Other characteristics were similar to those observed in cultures with SK but different from those induced by PGn (Tabl.2).

Effects of $P G n, P K, S K, P G n-P K$, and $S K-P K$ on cell viability and extracellular LDH activity. Cell viability in treated and control cultures was $90-98 \%$ for 1 day. In 3 days, cell viability in control fell down to $35 \%$. In treated cells, viability was $80-98 \%$, depending on the agent and its concentration.

Increased LDH activity in the culture medium was registered in the control after $24 \mathrm{~h}$. In 3 days, it was enhanced by a factor of 5 , whereas in cultures with added agents, extracellular LDH activity was reduced during the entire period of observation, except for $10^{-11} \mathrm{M}$ PGn, which did not reduce LDH activity more than in control cultures. In 3 days, $\mathrm{LDH}$ activity in cultures with $10^{-7} \mathrm{M}$ PGn and its complex with PK was higher than in cultures with PK, SK or their complex. Other differences in extracellular LDH activity in treated cultures were not recorded (Fig. 1).

IMR-32 cell morphology in cultures with PGn, PK, $S K$, or their equimolar complexes. Most of the cells in the control cultures were floating or round with either 

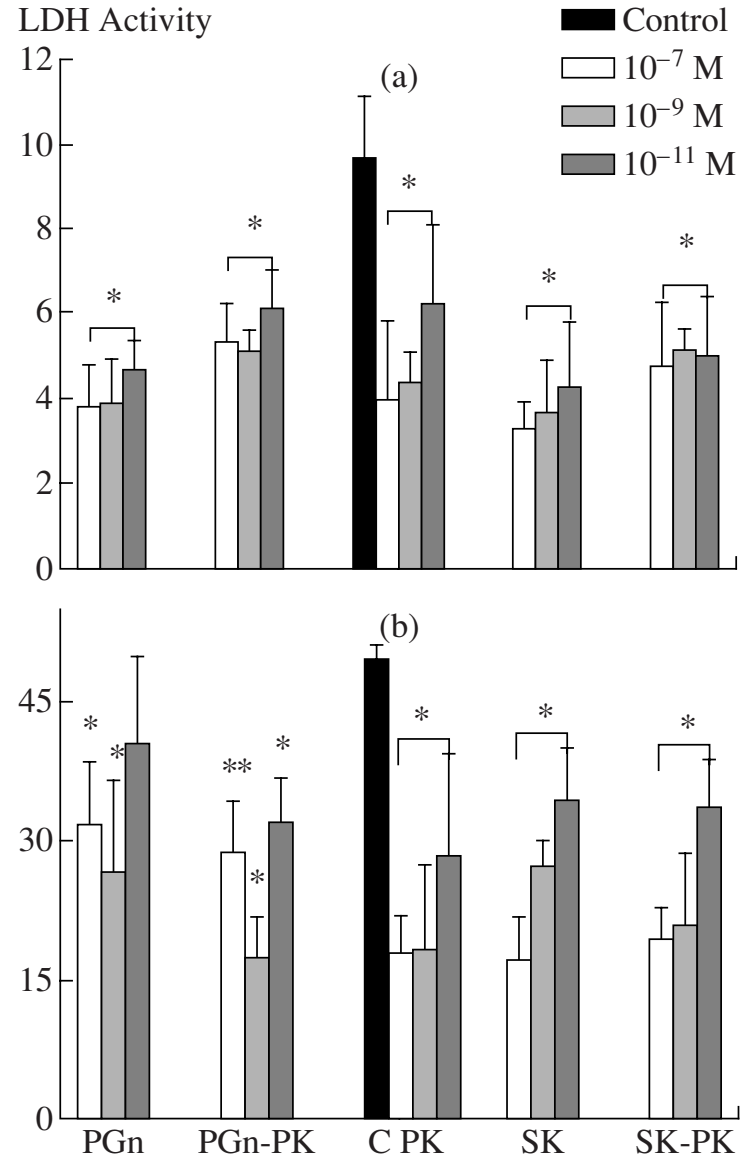

Fig. 1. LDH activity in culture medium of human neuroblastoma IMR-32 cells after 1 (a) and 3 (b) days of cultivation with $\mathrm{PGn}, \mathrm{SK}, \mathrm{PK}$, or their equimolar complexes. $\mathrm{LDH}$ activity is determined as nM NADH per min per $1 \mathrm{mg}$ protein; $(*)$ the difference between control and experimental groups are significant; $(* *)$ the difference between PGn and other agents is significant. The difference is determined by Mann-Whitney criteria $(p<0.05)$.

no or short processes. In cultures grown with $10^{-7} \mathrm{M}$ PGn, cells produced a monolayer. Floating or round cells were of rare occurrence. Differentiated cells with long processes (more than $50 \mu \mathrm{m}$ ) were observed. In cultures grown with SK for 3 days more round cells with short processes were seen than in cultures treated with PGn. The SK-PK complex prevented destructive events more effectively than SK alone. In cultures treated with $10^{-7}$ M PK or PGn-PK cells developed a dense monolayer and floating cells were not observed (Fig. 2).

$P G n, P K, S K$, and their equimolar complex effect on the PGn-activating function of IMR-32 neuroblastoma cells. It is known that neuroblastoma cells secrete 2 PGn activators, uPA, and tPA (Benjamin et al., 1989; Seeger et al., 1977). We have examined how the PGn activating capacity of neuroblastoma cells treated with agents changed during different periods. It was shown that cells in cultures grown with PK and PGn or their complex sustain the ability to activate PGn. SK stimulated the cell capacity of PGn activation; it was 3 times higher after 1 day and 6 times higher after 6 days. SKPK complex induced the enlargement of the lysis zone by a factor of 2.7 after 1 day, but later, the cultures were similar to control cultures (Table 3 ).

\section{DISCUSSION}

The plasminogen-plasmin system plays a key role in the regulation of cell proliferation and migration in embryogenesis tumor invasion and metastasis (Dana et al., 1985; Valinsky, Le Douarin, 1985). The paper presented confirmed the implication of the system in vital functions of human neuroblastoma. Cells cultivated with PGn had an increased content of DNA, RNA, and protein. Cell number and proliferation index were also higher than in control cultures. The findings show that the agents stimulate the proliferation of neuroblastoma cells. It was previously reported that the mitogenic action of PGn is abolished by a receptor inhibitor of the insulin-like growth factor and antibodies to $\mathrm{IGF}_{2}$ (Menouny et al., 1997). It is probable that PGn action is mediated via IGFs. For neuroblastoma cells, it is $\mathrm{IGF}_{2}$ as it is produced by these cells (El-Badry et al., 1989). The influence of IGFs on cell proliferation is well recognized (El-Badry et al., 1991). It was demonstrated that neurons express surface $\alpha$-enolase, which is a PGn receptor (Nakagima and Hamanoue, 1994). It is unclear whether neuroblastoma cells have $\alpha$-enolase on their surface, but it is well known that they express amphoterin. PGn, as well as tPA, is able to complex with amphoterin via lysine-binding sites and its binding leads to the acceleration of PGn activation (Parkkinen and Rauvala, 1991). Activated PGn is able to affect cell microenvironment, in particular to cause $\mathrm{IGF}_{2}$ activation. Moreover, extracellular LDH activity was lower in cultures with PGn, indicating that PGn is able to prevent membrane injury and cell death. This is confirmed by the findings on cell viability. The data are in agreement with the results we obtained earlier with rat pheochromocytoma PC12 that $10^{-6}-10^{-7}$ M PGn improved cell viability in serum-free cultures (Nikandrov et al., 2002). Taking into account that cell death in a serumfree medium is induced by the activation of free radicals (Sokolova et al., 2005), we assume that the PGn property of weak superoxide convergence (Nikandrov and Pyzhova, 2003b) prevents oxidative stress under serum deprivation.

We were the first to examine the influence of SK, a PGn activator, on neuroblastoma cells. SK facilitates cell viability and proliferation in serum-deficient media. Our previous study showed that SK affected neuronal cells directly, i.e., omitting the blood stream. It allows us to consider SK to be a regulator protein. The SK effect depends on the cell type, particularly tissue differentiation. It is highly probable that SK is a trigger and stabilizes the cell structure and function. As a result, cells stay viable under unfavorable conditions. 

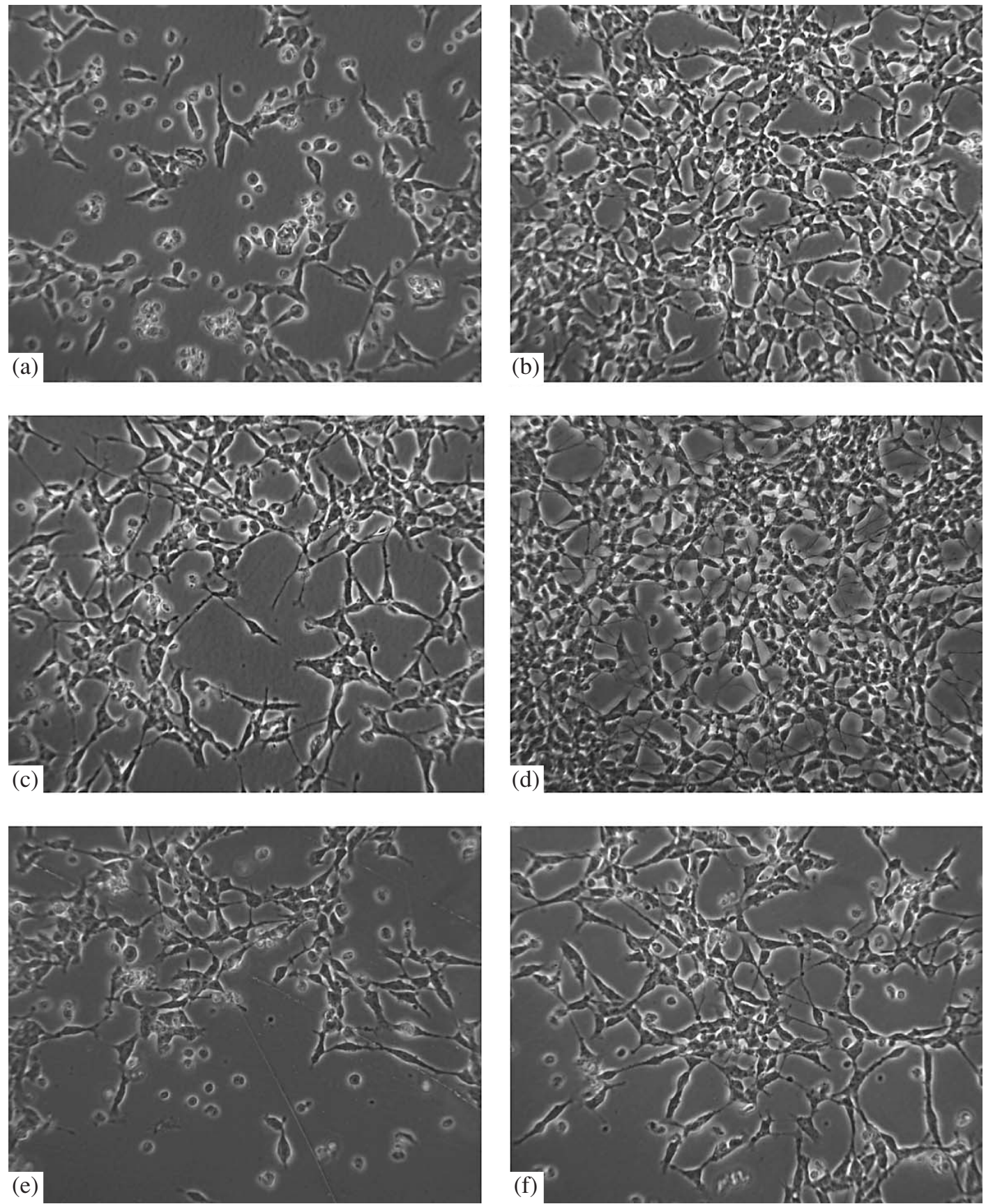

Fig. 2. IMR-32 cell growth in a serum-free medium (a) and in a medium with $10^{-7} \mathrm{M}$ agents (b-f). (b) PK; (c) PGn; (d) PGn-PK equimolar complex; (e) SK; (f) equimolar SK-PGn complex. Phase contrast; ob. 16×.

PK simulated cell proliferation even more than PGn or SK. PK influence depends on the cell type. Thus, it was found earlier that PK $\left(10^{-7} \mathrm{M}\right.$, in particular) inhibited the cell growth of rat glioma C6 (Romanovskaya, 2005).

The mechanisms underlying SK or PK regulation of cell viability and proliferation in nanomolar concentrations is still unclear. It seems unlikely that proteins disintegrated in growth media may be a supply of amino acids for cells, as the amount of the proteins added to cultures is very low. Most likely, the proteins are bound with some surface structures (receptors) responsible for cell proliferation. However, a nonreceptor pathway cannot be excluded. Thus, taking into consideration that even a low $\left(10^{-11} \mathrm{M}\right)$ concentration of PGn or SK enhanced the DNA, RNA, and protein content, as well as stimulated cell proliferation in 3-day cultivation, it is possible to suggest that the mechanisms underlying the protein action are based on transmembrane ion 
Table 3. PG-dependent fibrinolytic activity of human neuroblastoma cells IMR-32 after their cultivation with PG, PK, or $\mathrm{SK}$ or with their equimolar complexes (PG-PK; SK-PK)

\begin{tabular}{l|c|c}
\hline $\begin{array}{c}\text { Additions to the } \\
\text { cultivation } \\
\text { medium }\end{array}$ & $\begin{array}{c}\text { Zones of fibrinoly- } \\
\text { sis after one day, } \\
\mathrm{mm}^{2}\end{array}$ & $\begin{array}{c}\text { Zones of fibrinoly- } \\
\text { sis after 3 days, } \\
\mathrm{mm}^{2}\end{array}$ \\
\hline Control & $34 \pm 3$ & $34 \pm 3$ \\
PK & $35 \pm 13$ & $39 \pm 3$ \\
PGn & $29 \pm 6$ & $38 \pm 9$ \\
SK & $105 \pm 21^{\mathrm{a}}$ & $205 \pm 17^{\mathrm{b}}$ \\
PGn-PK & $27 \pm 9$ & $51 \pm 15$ \\
SK-PK & $93 \pm 14^{\mathrm{a}}$ & $50 \pm 14$ \\
\hline
\end{tabular}

${ }^{a}$ Differences from control are statistically significant.

b Differences in comparison with 1 day of incubation are statistically significant. Statistical significance of differences was evaluated by using Mann-Whitney criterion for nonparametric samples $(p<0.05)$. Concentration of agent in all cases was $10^{-7} \mathrm{M}$.

exchanges, particularly $\mathrm{Ca}^{2+}$ ions. Further investigations will clarify the problem.

Thus, we obtained new facts on the initiation of cell malignization and tumor growth.

The work is supported by grant from Presidium of NAN, Belarus (no. 2006324).

\section{REFERENCES}

1. Benjamin, L.A., McGarry, R.C., and Hart, D.A., Effect of Retinoic Acid on Human Neuroblastoma: Correlation between Morphological Differentiation and Changes in Plasminogen Activator and Inhibitor Activity, Cancer Chemother. Pharmacol., 1989a, vol. 25, pp. 25-31.

2. Benjamin, L.A., McGarry, R.C., and Hart, D.A., Alterations in Plasminogen Activator and Inhibitor Activity during the Differentiation of a Human Neuroblastoma Cell Line, SMS-KAN, Cancer Lett., 1989b, vol. 44, pp. 101-108.

3. Dana, K., Andreasen, P.A., Grendahl-Hansen, J., Kristensen, P., Nielsen, L.S., and Ckriver, L., Plasminogen Activators, Tissue Degradation and Cancer, Adv. Cancer. Res., 1985, vol. 44, pp. 139-266.

4. El-Badry, O., Helman, L.J., Chatten, J., Steinberg, S.M., Evans, A.E., and Israel, M.A., Insulin-like Growth Factor 2 Mediated Proliferation of Human Neuroblastoma, J. Clin. Invest., 1991, vol. 87, pp. 648-657.

5. El-Badry, O., Romanus, J.A., Helman, L.J., Cooper, M.J., Rechler, M.M., and Israel, M.A., Autonomous Growth of a Human Neuroblastoma Cell Line is Mediated by Insulin-like Growth Factor 2, J. Clin. Invest., 1989, vol. 84, pp. 829-839.

6. Koh, J.Y. and Choi, D.W., Quantitative Determination of Glutamate Mediated Cortical Neuronal Injury in Cell Culture by Lactate Dehydrogenase Efflux Assay, J. Neurosci. Methods., 1987, vol. 20, pp. 83-90.
7. Liu, H.Y., Yang, P.P., Toledo, D.L., and Mangel, W.F., Modulation of Cell-associated Plasminogen Activator Activity by Cocultivation of a Stem Cell and its Tumorogenic Descendant, Moll. Cell. Biol., 1984, vol. 4, pp. 160-165.

8. Menouny, M., Binoux, M., and Babajko, S., Role of Insulin-like Growth Factor Binding Protein 2 and Its Limited Proteolysis in Neuroblastoma Cell Proliferation: Modulation by Transforming Growth Factor-beta and Retinoic Acid, Endocrinol., 1997, vol. 138, pp. 683690.

9. Nakagima, K. and Hamanoue, M., Plasminogen Binds Specifically to $\alpha$-Enolase on Rat Neuronal Plasma Membrane, J. Neurochem., 1994, vol. 63, pp. 2048-2057.

10. Nikandrov, V.N., Murashko, O.N., Vorobyova, G.V., Pyzhova, N.S., Kvyatkovskaya, N.V., and Bartalevich, O.A., Integration of Human Plasminogen or Streptokinase into Stable Complexes with Oxidoreductases and Pyruvate Kinase, Letters Pept. Sci., 1997, vol. 4, pp. 497-502.

11. Nikandrov, V.N. and Pyzhova, N.S., Regulatory Proteins: Functions and Mechanisms, Isvest. NAN Belarus, Med.-biol. Ser., 2003b, vol. 3, pp. 75-89.

12. Nikandrov, V.N. and Zhuk, O.N., Streptokinase Effect on the Development of Rat Cerebral Cortex in vitro, Morphologia, 2005, vol. 128, pp. 33-36.

13. Nikandrov, V.N., Nikandrov, V.N., Petrusenko, G.P., and Gronskaya R.I., ATP- and $\mathrm{Ca}_{2}$-Dependent Proteolysis in PC12 Pheochrocytoma Cells Treated with Streptokinase and Nerve Growth Factor, Isvest. NAN Belarus, Med.biol. Ser., 2003a, vol. 4, pp. 84-87.

14. Nikandrov, V.N., Petrusenko, G.P., Zhuk, O.N., Polukoshko, E.F., Volodkevich, O.I., Lukashevich, I.B., Gronskaya, R.I., Shpak, G.A., Tumilovich, M.K., and Pyzhova, N.S., Effect of Pericellular Proteolysis Components on Nerve Cells, Dostig. Med. Nauk Belarus, 2002, vol. 7, pp. 49-50.

15. Nikandrov, V.N., Pyatin, V.F., Alekseeva, A.S., Miroshnichenko, I.V., Jakunina, O.V., Novoselova, A.M., Garkun, Yu.S., Murashko, O.N., and Kul'chitskii, B.A., Modulation of Central Respiratory Activity with Plasminogen, Streptokinase and Their Complexes with Pyruvate Kinase, Nov. med.-Biol. Nauk, vol. 2, pp. 40-43.

16. Parkkinen, J. and Rauvala, H., Interaction of Plasminogen and Tissue Plasminogen Activator (t-PA) with Amphoterin. Enhancement of t-PA-Catalyzed Plasminogen Activation by Amphoterin, J. Biol. Chem., 1991, vol. 266, pp. 16730-16735.

17. Romanovskaya, A.A., C6 Glioma Growth Treated with Various Concentrations of Pyruvate, Isvest. NAN Belarus, Med.-biol. Ser., 2005, vol. 5, pp. 38-41.

18. Puglianiello, A., Germani, D., Rossi, P., and Cianfarani, S., IGF-I Stimulates Chemotaxis of Human Neuroblasts. Involvement of Type 1 IGF Receptor, IGF Binding Proteins, Phosphatidylinositol-3 Kinase Pathway and Plasmin System, J. Endocrinol., 2000, vol. 165, pp. 123-131. 
19. Pyzhova, N.S., Nikandrov, V. N., and Nikandrov, N.N., Effect of Active Oxygen Species Scavengers on Fibrinolytic Activity of Some Proteinases, Thromb. Res., 1996, vol. 82, pp. 303-312.

20. Schmidt, G. and Thannhauser, S.J., A Method for the Determination of Desoxyribonucleic Acid, Ribonucleic Acid and Phosphorproteins in Animal Tissues, J. Biol. Chem., 1945, vol. 161, pp. 83-89.

21. Seeger, R.C., Rayner, S.A., Banerjee, A., Chung, H., Laug, W.E., Neustein, H.B., and Benedict, W.F., Morphology, Growth, Chromosomal Pattern and Fibrinolytic
Activity of Two New Human Neuroblastoma Cell Lines, Cancer Res., 1977, vol. 37, pp. 1364-1371.

22. Sokolova, T.V., Furaev, V.V., Jurlova, L.A., and Avrova, N.F., Effect of Ganglioside GM1 on Intracellular Concentration of Free Calcium and Viability of PC12 Cells under Oxidative Stress, Neurochimia, 2005, vol. 22, pp. 266-272.

23. Valinsky, J.E. and Le Douarin, N.M., Production of Plasminogen Activator by Migrating Cephalic Neural Crest Cells, EMBO J., 1985, vol. 4, pp. 1403-1406. 